\title{
Urban Climate Projection by the WRF Model at 3-km Horizontal Grid Increment: Dynamical Downscaling and Predicting Heat Stress in the 2070's August for Tokyo, Osaka, and Nagoya Metropolises
}

\author{
Hiroyuki KUSAKA \\ Center for Computational Sciences, University of Tsukuba, Tsukuba, Japan \\ Masayuki HARA \\ Japan Agency for Marine-Earth Science and Technology, Yokohama, Japan \\ and \\ Yuya TAKANE \\ Graduate School of Life and Environmental Sciences, University of Tsukuba, Tsukuba, Japan \\ (Manuscript received 30 June 2011, in final form 22 December 2011)
}

\begin{abstract}
This study presents the projected urban climate for the 2070s' August in the three largest urban areas, Tokyo, Osaka, and Nagoya in Japan. To accurately evaluate the urban climate, the simulations use the Weather Research and Forecast (WRF) model with 3-km grid increment coupled to an urban canopy model (UCM). To project future urban climate, the simulations apply dynamical downscaling to three GCMs (MIROC3.2-medres, MRI-CGCM2.3.2a, CSIRO-Mk3.0) and use the ensemble average for results. The results provide estimates of the heat stress to future residents of Tokyo, Osaka, and Nagoya.

The WRF-UCM model reproduces the observed spatial distribution of the surface air temperature in the 2000s' August, giving an all-domain mean bias of $-1.2^{\circ} \mathrm{C}$ and RSME of $2.7^{\circ} \mathrm{C}$. For Tokyo, Nagoya, and Osaka, these biases are $-0.6,-0.1$, and $-0.4^{\circ} \mathrm{C}$. Moreover, the diurnal temperature variations at these urban stations are well reproduced. The projected monthly average August temperatures in the 2070 s are about $2.3^{\circ} \mathrm{C}$ higher than those in the 2000s at the three urban areas and comparable to those in the record-breaking hot summer of 2010. (Predictions by individual ensemble members differ by $0.8-1.2^{\circ} \mathrm{C}$.) As a result, urban areas will experience uncomfortable sleeping nights nearly every day in August, with roughly as many heat-induced sleeping-discomfort nights as those in 2010. Moreover, application of the wet-bulb globe temperature (WBGT) shows that people in Tokyo will be warned not to strenuously exercise outdoors for $62 \%$ of the daytime hours in the 2070 s, a sharp increase from the $30 \%$ of the 2000s. (Predictions by individual ensemble members range from 54-67\%). Osaka and Nagoya will have even more restrictions on outdoor exercise. Finally, the urban heat island intensity is $1.5^{\circ} \mathrm{C}$ in Tokyo of the $2070 \mathrm{~s}$, comparable to the background climate warming of $2.3^{\circ} \mathrm{C}$.
\end{abstract}

Corresponding author: Hiroyuki Kusaka, Center for Computational Sciences, University of Tsukuba, Tsukuba, 305-8572, Japan. E-mail:kusaka@ccs.tsukuba.ac.jp

(C) 2012, Meteorological Society of Japan

\section{Introduction}

Greater Tokyo is the world's largest metropolitan area, with a population of about 32.5 million. Over the past 100 years, its annual mean surface air temperature has been trending upwards (Japan 
Table 1. Monthly climatology at urban and rural stations in August for 2000-2009. Nerima and Sakai had no RH measurements. Hereafter, Otemachi is called Tokyo in this study.

\begin{tabular}{lccccc}
\hline & $\begin{array}{c}\text { Daily mean } \\
\text { Temperature }\left[{ }^{\circ} \mathrm{C}\right]\end{array}$ & $\begin{array}{c}\text { Daily Maximum } \\
\text { Temperature }\left[{ }^{\circ} \mathrm{C}\right]\end{array}$ & $\begin{array}{c}\text { Daily Minimum } \\
\text { Temperature }\left[{ }^{\circ} \mathrm{C}\right]\end{array}$ & $\begin{array}{c}\text { Relative } \\
\text { humidity }[\%]\end{array}$ & $\begin{array}{c}\text { Discomfort } \\
\text { Index }\end{array}$ \\
\hline Otemachi (Tokyo) & 27.4 & 31.2 & 24.5 & 69 & 77 \\
Nerima & 27.2 & 31.8 & 23.8 & - & - \\
Nagoya & 28.0 & 33.2 & 24.5 & 68 & 78 \\
Osaka & 28.9 & 33.6 & 25.6 & 64 & 79 \\
Sakai & 28.4 & 33.6 & 24.4 & 87 & 76 \\
Chosi & 25.2 & 28.2 & 21.7 & 77 & 75 \\
17 rural stations & 25.3 & 29.2 & & & - \\
Average & & & & & \\
\hline
\end{tabular}

Meteorological Agency, 2009). And because Tokyo is warming faster than rural areas, urbanization may be a primary factor for this trend (e.g., Fujibe 2009). However, over the past 30 years, the warming rate of the rural areas has approached that of Tokyo, which instead suggests that the primary factor behind the recent warming in Tokyo has been a background climate change.

Tokyo is already notable for its exceedingly uncomfortable summers, with an average August temperature of $27.4^{\circ} \mathrm{C}$, a humidity of $69 \%$, and a discomfort index of 77 (Table 1). As a result, heat stroke routinely hospitalizes people in Tokyo. Ambulances transported 4,245 people with heat stroke to the hospitals in Tokyo in 2010 summer (Fire and Disaster Management Agency of Japan 2011). The number of deaths caused by heat stroke has been exceeding the deaths from other weather disasters, including typhoons and tornados in recent years in Japan (Fujibe 2009), and was 272 people in Tokyo in 2010 (Ministry of Health, Labor and Welfare 2011). More common is sleep disruption from the urban warming, which adversely affects health and leads to associated economic losses. For instance, Ihara and Genchi (2009) have reported that the increase in disturbed sleep resulting from the UHI effect at night in the past 30 years caused health damage, and the environmental impact reaches to 13,500 million yen per year in Tokyo with endpoint-type impact assessment methodology. It is larger than damage due to heat stroke which is estimated to be 1,870 million yen. Moreover, an increase in the daytime high by $1^{\circ} \mathrm{C}$ in summer increases daily maximum energy demand by about $1,900,000 \mathrm{~kW}$ in the Tokyo metropolitan area and its surroundings, as a result of increased airconditioning demand (e.g., Goto et al. 2004). With such adverse effects from present summertime heat, how worse will the urban environment be in the future?

According to the IPCC Fourth Assessment Report, global mean temperature is projected to increase (e.g., Fig. 1), and Japanese summer is not an exception (Table 2). Unless it is mitigated by other changes, the progression of urban warming should increase the economic losses and energy consumption as well as the incidences of sleep disruption and heat stroke. These effects greatly concern urban residents, especially in the three major metropolitan areas of Tokyo, Nagoya, and Osaka. To ensure an effective response to these concerns, projection of future urban climate is needed.

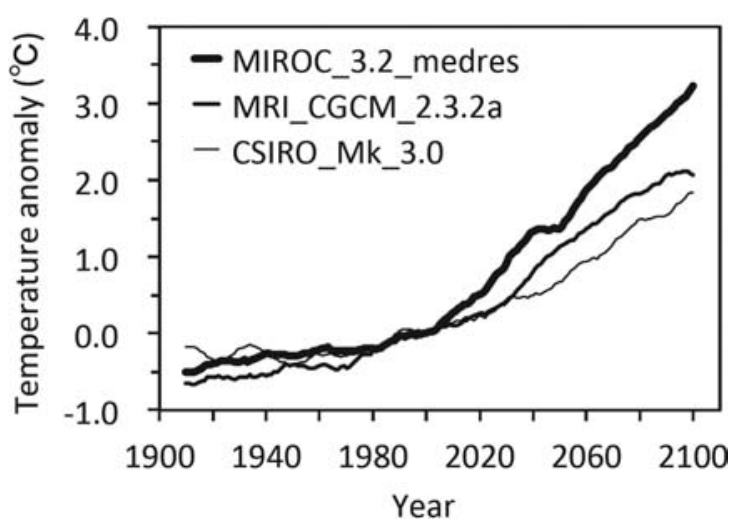

Fig. 1. Projected global mean temperature increase at $1000 \mathrm{hPa}$ over that from the 1990s. All lines show decadal running average. MIROC_3.2_medres, MRI_CGCM_2.3.2a, CSIRO_Mk3.0 are three CMIP3 GCMs under the SRES A1b Scenario. 
Table 2. Ten-year averaged increase in August air temperatures at $925 \mathrm{hPa}$ from three GCMs (MIROC, MRI, CSIRO). The baseline temperature is the 20002009 average. Region is $130-150 \mathrm{E}, 30-50 \mathrm{~N}$.

\begin{tabular}{lccc}
\hline & MIROC & MRI & CSIRO \\
\hline $2030 \mathrm{~s}$ & 1.4 & 1.1 & 0.9 \\
$2050 \mathrm{~s}$ & 2.3 & 1.2 & 0.9 \\
$2070 \mathrm{~s}$ & 3.3 & 2.6 & 1.7 \\
$2090 \mathrm{~s}$ & 3.8 & 2.3 & 2.2 \\
\hline
\end{tabular}

Recently, Oleson et al. (2010) and McCarthy et al. (2010) started work on these issues using GCMs with an urban canopy model (UCM) that can represent the influences of urban geometry and anthropogenic heat emission. Although these climate models have improved the representation of urban surfaces, their spatial resolution is too coarse to describe Japanese metropolitan areas. To increase the resolution, an effective approach is dynamical downscaling (DDS) with a regional climate model (RCM). The DDS approach has been improved by many scientists since Dickinson et al. (1989), Giorgi and Bates (1989), and Kida et al. (1991), such that today the horizontal grid spacing is $5 \mathrm{~km}$ or less (e.g., Sasaki et al. 2008, Kitoh et al. 2009, Kusaka et al. 2010, Rasmussen et al. 2011, Liu et al. 2011, Kanada et al. 2011).

RCMs with less than $5-\mathrm{km}$ grid spacing have been recently used to project future urban climate, but they are relatively few in number. Hara et al. (2010) used the Weather Research Forecasting (WRF, Skamarock et al. 2008) model with 3-km horizontal grid spacing coupled to a single-layer UCM to project the urban climate of the 2070s in Japan, although the time integration was limited to December of a specific year. Similar research has been done by Iizuka et al. (2010), but for August of a specific year. To study the Houston, USA region, Shepherd et al. (2010) used MM5 (the fifthgeneration Mesoscale Model; Dudhia et al. 1993, Grell et al. 1994) with an urban scenario for 2025, but it was a case study for a specific day, and the initial and boundary conditions were created from present analysis data. The impact of future climate change over the Houston area has also been examined by the WRF/UCM/Chemistry modeling system with 4-km horizontal grid spacing (e.g., Jiang et al. 2008). Finally, a unique study on future climate in Frankfurt, Germany has been done using a RCM and UCM with a relatively coarse resolution (Fruh et al. 2011).

The present study thus has two purposes. One, we use the coupled WRF-LSM-UCM model with 3-km horizontal grid spacing to project the urban climate in the 2070s' August for Tokyo, Osaka, and Nagoya. Two, we apply these projections to assess the impact of urban warming on the heat stress to the residents. Results from the present study should also contribute to advanced impact assessment research (e.g., Honda et al. 1998, Takahashi et al. 2007, Miller et al. 2008, Ihara et al. 2008, 2011, Ihara and Genchi 2009).

\section{Dynamical downscaling for current-urban climate and its verification}

\subsection{Design of the numerical experiment}

Although the WRF model has been used for numerical weather predictions, few studies (i.e., Miao et al. 2009, Chen et al. 2010, Kusaka et al. 2012) have applied it to a multi-year urban climate simulation with a coupled UCM. Therefore, we first evaluate the modeling system against current observations before applying it to future climate prediction. Then, when we apply it to future climate, we use an ensemble of three, carefully selected GCMs because previous studies have established that the boundary conditions, which will come from the GCMs, strongly affect projected results from RCMs.

The model evaluation on current climate also serves as a control case, hereafter case CTRL. For CTRL, we apply dynamical downscaling with the WRF model. Using the terminology of Castro et al. (2005), the downscaling is a type-2 dynamical downscaling in which the results are independent of the initial atmospheric conditions, yet still dependent on the lateral boundary conditions (from global analysis data) and on the bottom boundary conditions. CTRL is a simple hindcast run using 6-hourly NCEP-Final analysis (FNL) data for the boundary conditions, including sea surface temperature (SST).

The model uses the nesting approach for the domains (Fig. 2a). The smallest domain, D03, covers central Japan, which includes the three major metropolitan areas that we focus on (Figs. $2 \mathrm{~b}$ and $2 \mathrm{c}$ ). In this domain, we set the horizontal grid spacing at $3 \mathrm{~km}$, the model top at $50 \mathrm{hPa}$, and use 31 vertical sigma levels. For the land-use and terrain-height data, we use the set created by the Geospatial Information Authority of Japan. 

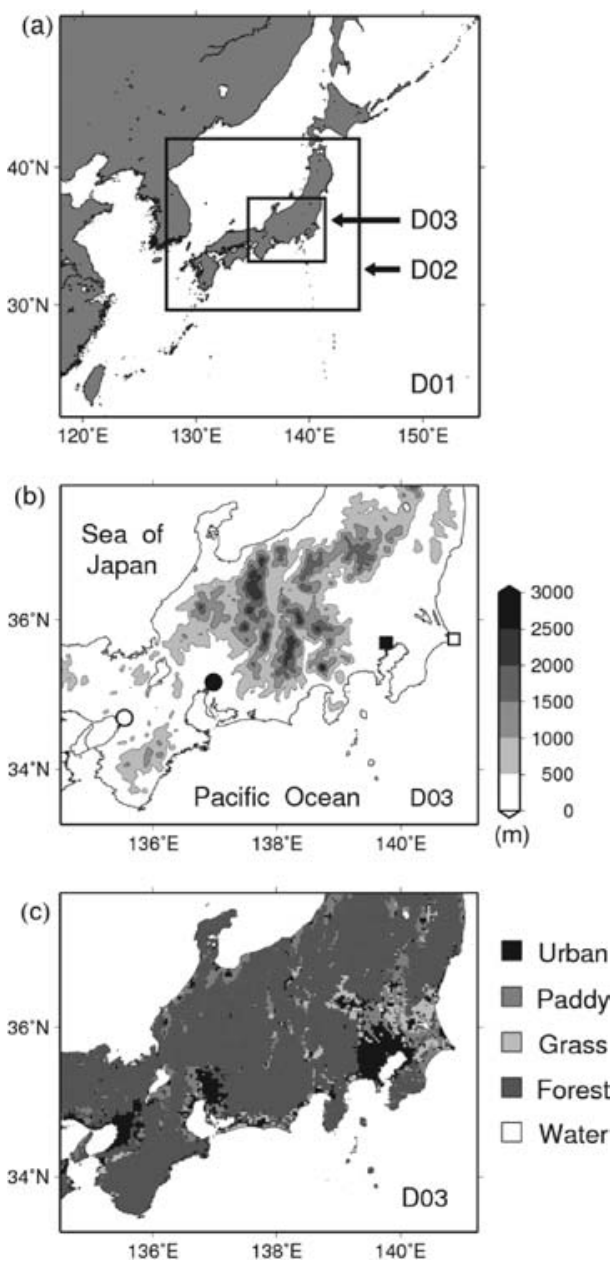

Fig. 2. Location, topography, and land-use of the model domains. (a) Location of the outer parent domain D01 within east Asia and the nested child (D02) and grandchild (D03) sub-domains. (b) Topography of central Japan. Open square $=$ Chosi, solid square $=$ Tokyo, open circle $=$ Osaka, and solid circle = Nagoya cities. (c) Land-use of central Japan. Black, dark gray, medium gray, light gray, and white indicate urban, forest, rice paddy, grassland, and water surfaces, respectively.

The following physics schemes are used in the experiments: the Dudhia shortwave radiation model (Dudhia 1989), the RRTM longwave radiation model (Mlawer et al. 1997), the WSM3 cloud microphysics model (Hong et al. 2004), the YSU planetary boundary layer model (Hong and Pan 1996, Hong et al. 2006), and the Noah land surface model (Chen and Dudhia 2001) with a single-layer

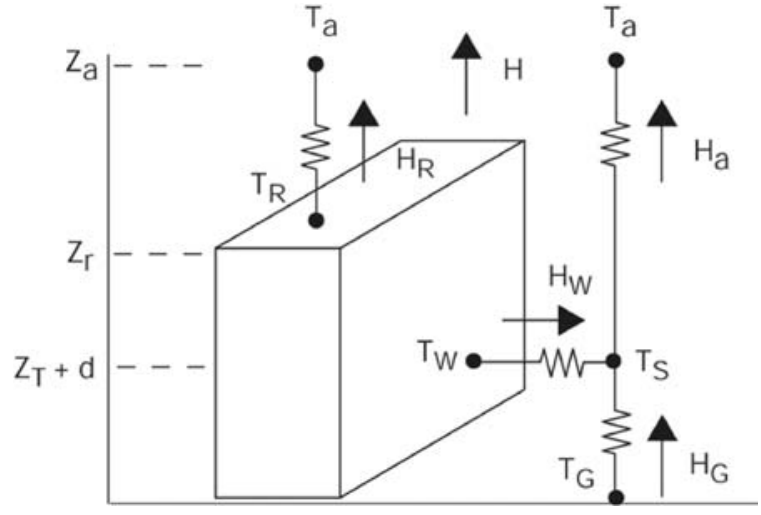

Fig. 3. Temperatures and heat fluxes in the single-layer UCM. $T_{a}$ is the temperature of the air at reference height $z_{a}, T_{G}$ is that for the road, $T_{S}$ is that at height $z_{T}+d$, and $T_{R}$ and $T_{W}$ are those of the building roof and wall. $H$ is the sensible heat exchange at $z_{a} . H_{a}$ is the sensible heat flux from the canyon space to the atmosphere, whereas $H_{W}$ is that from wall to the canyon space, $H_{G}$ is that from the road to the canyon space, and $H_{R}$ is that from the roof to the atmosphere.

Table 3. Parameters for the single-layer UCM. Value in parenthesis is the gross building coverage ratio.

\begin{tabular}{ll}
\hline Parameter & Value \\
\hline Green fraction $[-]$ & 0.3 \\
Building height [m] & 9 \\
Building coverage ratio [-] & $0.35(0.245)$ \\
Sky view factor [-] & 0.59 \\
Daily mean anthropogenic heat & 18 \\
$\quad$ emission [W m ${ }^{-2}$ ] & \\
\hline
\end{tabular}

UCM (Kusaka et al. 2001, Kusaka and Kimura 2004a, b). In addition, for D01 and D02, we use the Kain-Fritch cumulus parameterization scheme (Kain and Fritch 1990, Kain 2004). The UCM (Fig. 3) considers the urban geometry, green fraction, and anthropogenic heat emission with diurnal variation at the urban grid. For parameter values, we use the average values for the Tokyo Metropolitan Area, as listed in Table 3.

\subsection{Reproducibility of the WRF model with UCM}

For the CTRL case, we first compare the resulting surface air temperatures from the WRF model simulation to observations from the Automated 


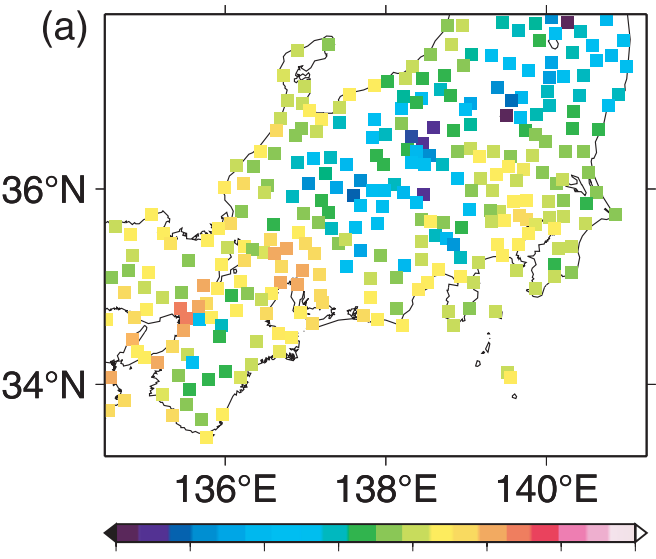

$\begin{array}{lllllllll}18 & 20 & 22 & 24 & 26 & 28 & 30 & 32\end{array}$ $\left({ }^{\circ} \mathrm{C}\right)$

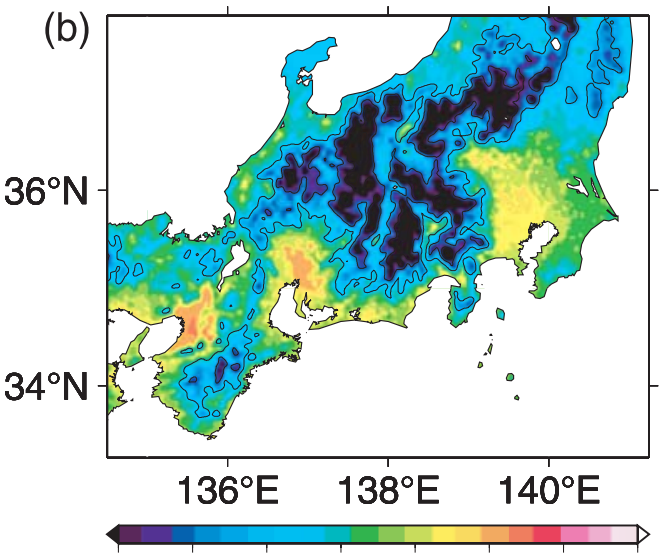

$\begin{array}{lllllllll}18 & 20 & 22 & 24 & 26 & 28 & 30 & 32\end{array}$

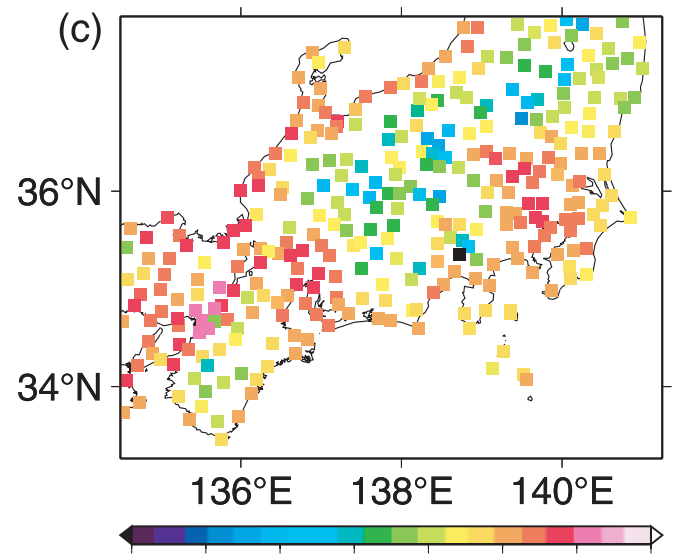

$\begin{array}{lllllllll}18 & 20 & 22 & 24 & 26 & 28 & 30 & 32 & \left({ }^{\circ} \mathrm{C}\right)\end{array}$

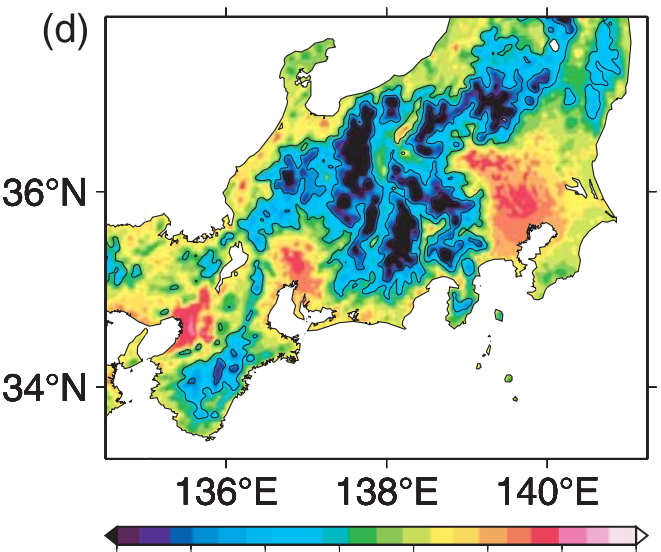

$\begin{array}{lllllllll}18 & 20 & 22 & 24 & 26 & 28 & 30 & 32 & \left({ }^{\circ} \mathrm{C}\right)\end{array}$

Fig. 4. Spatial distribution of August monthly mean surface air temperature, averaged for years 2000-2009.

(a) AMeDAS observations. (b) CTRL case. (c) Same as (a), but for 2010. (d) Same as (b), but for 2010.

Meteorological Data Acquisition System (AMeDAS) network operated by the Japan Meteorological Agency (JMA). To account for differences in the terrain height between the model grid and the observation site, we assume a temperature lapse rate of $0.0065^{\circ} \mathrm{C} \mathrm{m}^{-1}$.

The WRF model successfully reproduces essential features of the temperature distribution, averaged for August, 2000-2009 (Figs. 4a,b). In particular, the three major metropolitan areas are warmer than their surroundings, and the Osaka and $\mathrm{Na}$ goya metropolitan areas are warmer than Tokyo. However, the model underestimates the temperature in the coastal area of the Sea of Japan and over the mountains. The error distribution of the entire domain is roughly normally distributed (Fig. 5). The bias, RMSE, and correlation over the entire domain are $-1.2^{\circ} \mathrm{C}, 2.7^{\circ} \mathrm{C}$, and 0.82 , respectively

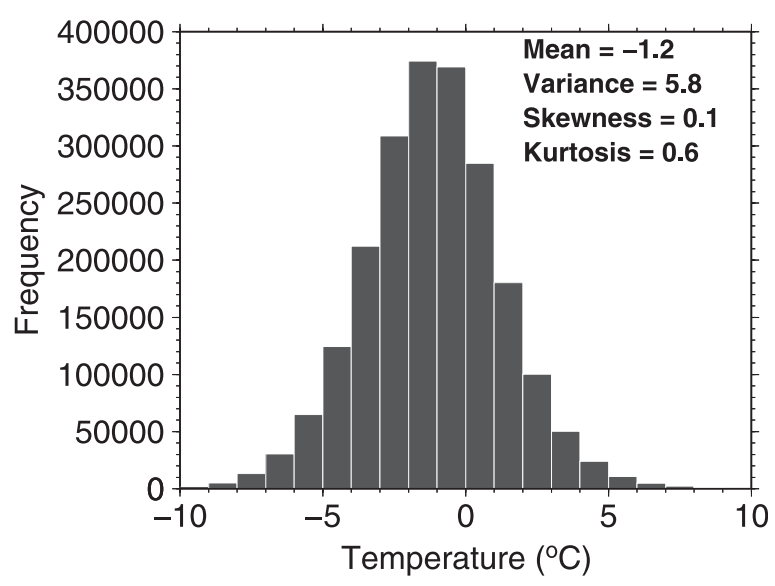

Fig. 5. Error distribution of the simulated surface air temperature for the CTRL case (2000s' August) within domain D03. WRF minus AMeDAS. 
Table 4. Comparison of surface air temperatures between observations and the WRF-UCM simulations for the entire D03 domain and five urban stations.

\begin{tabular}{lccc}
\hline & $\operatorname{Bias}\left[{ }^{\circ} \mathrm{C}\right]$ & $\mathrm{RMSE}\left[{ }^{\circ} \mathrm{C}\right]$ & Correlation \\
\hline Entire Domain & -1.2 & 2.7 & 0.82 \\
Tokyo & -0.6 & 2.3 & 0.74 \\
Nerima & -0.3 & 2.4 & 0.76 \\
Nagoya & -0.1 & 1.9 & 0.81 \\
Osaka & -0.4 & 2.0 & 0.77 \\
Sakai & +0.1 & 2.2 & 0.76 \\
\hline
\end{tabular}

(Table 4). Similarly, the temperature distribution in the record-breaking hot summer of 2010 is also reproduced well, although the bias is more negative (Figs. 4c,d).

The high resolution of the present model allows us to compare results to specific urban stations. In particular, at the Otemachi AMeDAS station (hereafter, Tokyo station), located in the office area of Tokyo, the bias is $-0.6^{\circ} \mathrm{C}\left(26.8\right.$ vs $\left.27.4^{\circ} \mathrm{C}\right)$ and the RSME is $2.3^{\circ} \mathrm{C}$ (Table 4). But at Nerima station, located in a residential area of Tokyo, the bias is $-0.3^{\circ} \mathrm{C}$ and RSME is $2.4^{\circ} \mathrm{C}$. The model was more accurate in Nagoya, an urban area further south, where the bias and RMSE at Nagoya station (also in a residential area) are $-0.1^{\circ} \mathrm{C}$ and $1.9^{\circ} \mathrm{C}$, respectively. Similarly, in a residential area of Osaka (Sakai station), the bias and RSME are $+0.1{ }^{\circ} \mathrm{C}$ and $2.2^{\circ} \mathrm{C}$. But in an office area of Osaka city (Osaka station), the bias is $-0.4^{\circ} \mathrm{C}$ and $\mathrm{RSME}$ is $2.0^{\circ} \mathrm{C}$, Thus, the model bias is larger and more negative in more urbanized areas. Moreover, we found the error distributions for Tokyo, Nerima, Nagoya, Osaka, and Sakai stations to be normally distributed, similar to that of the entire domain.

Concerning the diurnal variations of the averaged monthly mean surface air temperature (2000s' August), the WRF model reproduces the observations well. For Tokyo station (Fig. 6a), the monthly mean daily maximum temperature from the simulation is $30.1{ }^{\circ} \mathrm{C}$, which nearly equals observations, but the model underestimates the monthly mean daily minimum temperature, predicting $24.5^{\circ} \mathrm{C}$ instead of the observed $25.3^{\circ} \mathrm{C}$. As a result, a simulated diurnal variation of $5.6^{\circ} \mathrm{C}$, which exceeds the observed value by $0.8^{\circ} \mathrm{C}$. This overestimate occurs because the present experiment uses the urban parameters averaged over the entire Tokyo metropolitan area, which then overestimates nocturnal cooling in the more urbanized regions, such as the
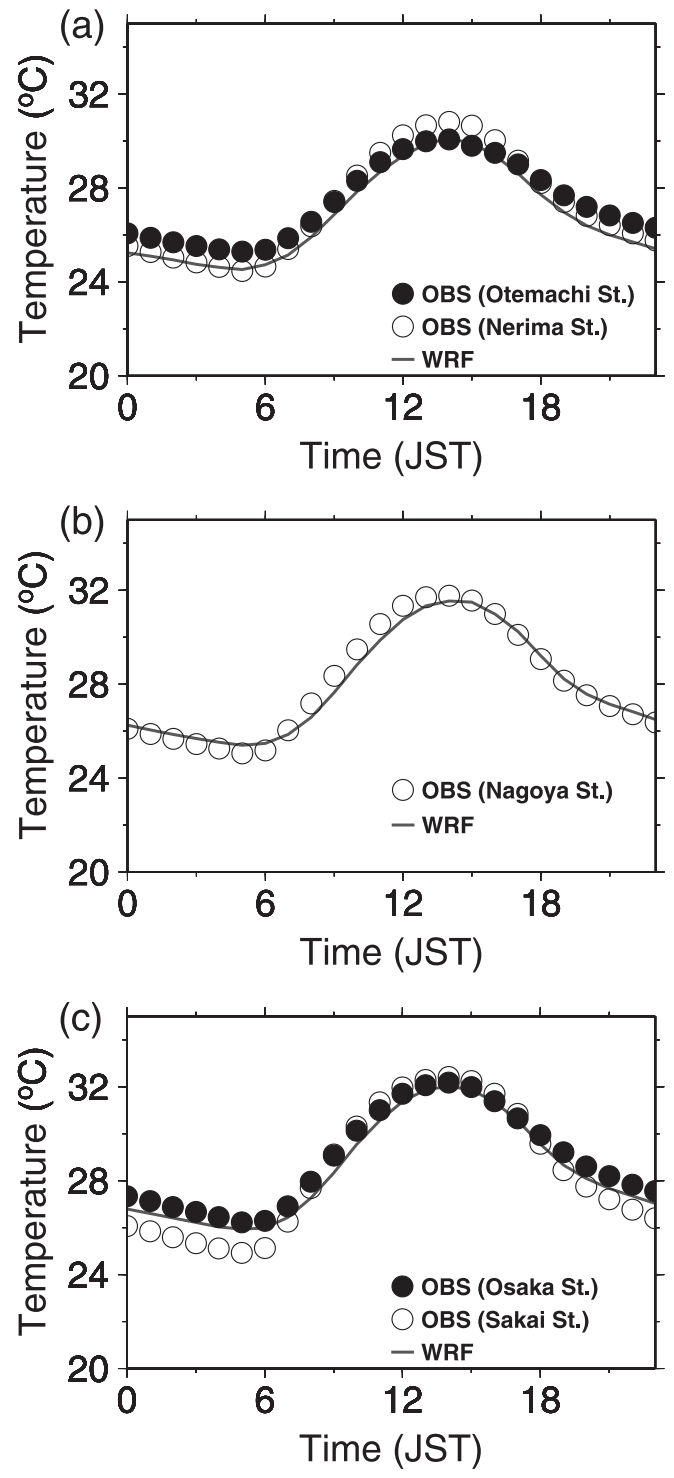

Fig. 6. Diurnal variation in surface air temperatures from observations and CTRL simulations. Temperatures are 10-yearaveraged values from 2000 to 2009. (a) Closed and open circles indicate the observed temperature at Tokyo and Nerima stations. Solid line is the simulated temperature at the nearest grid point to Tokyo station. (b) Open circles indicate the observed temperature at Nagoya station. Solid line is the simulated temperature at the nearest grid point to Nagoya station. (c) Closed and open circles indicate the observed temperatures in Osaka and Sakai stations, respectively. Solid line is the simulated temperature at the nearest grid point to Osaka station. 
office areas. Indeed, the model reproduces nocturnal cooling at Nerima station well, although the daily maximum temperature is overestimated. And as expected from the use of the average parameters, the simulated diurnal range with $5.6^{\circ} \mathrm{C}$ lies between the measured values at Tokyo and Nerima stations.

The diurnal variations also reproduce observations in Nagoya and Osaka. At Nagoya station, where the model bias is only $-0.2^{\circ} \mathrm{C}$ for the monthly mean temperature, differences in the monthlymean maximum, minimum, and diurnal range between the observations and simulations are only $0.3,0.3$, and $0.6^{\circ} \mathrm{C}$, respectively (Fig. 6b). The agreement is better than that in Tokyo because Nagoya station lies in a residential area. Residential station conditions are closer to the metropolitanarea average parameters for the urban geometry, urban fraction, and anthropogenic heat emission that the model assumes. Finally, the difference in the diurnal variation between Osaka and Sakai stations (Fig. 6c) is similar to that between Tokyo and Nerima stations-just as their urban parameters have a similar difference. However, the diurnal range at Sakai station is relatively large. This might to because the distance from downtown Osaka to Sakai station is greater than that from downtown Tokyo to Nerima station. Overall, Osaka is more similar to Tokyo, and Nagoya has better results.

\section{Dynamical downscaling for urban climate projection in the $2070 \mathrm{~s}$}

\subsection{Experimental design}

For these experiments, we apply the pseudo global warming (PGW) method, developed by Kimura and Kitoh (2007), to urban climate projection in the 2070s. An advantage of this method is the ability to reduce GCM climate bias by using modified objective analysis/re-analysis data instead of
GCM outputs. The boundary conditions are given by the summation of the present weather conditions and global warming components (Fig. A). And like the CTRL cases, the PGW method also uses type-2 dynamical downscaling. This approach has been applied to the WRF model with 5-km horizontal grid spacing for snow depth projection in winter (Hara et al. 2008) and to the WRF model with 3$\mathrm{km}$ horizontal grid spacing for urban climate projection in winter (Hara et al. 2010).

The current weather conditions come from the NCEP Final Analysis (NCEP-FNL) six-hourly data, whereas the global warming components are created from the difference in monthly climatology between the 10-year average of the 21st Century projection and the 20th Century simulation by the GCM. We assume the SRES-A1b (IPCC 2007) emission scenario. Because dynamical downscaling suffers from large uncertainties resulting from forcing GCMs (Mearns et al. 2003), we took an ensemble approach by averaging results from multiple GCMs to create boundary forcing. Specifically, we construct three distinctive future climate boundary conditions using outputs from three CMIP3 GCM models: CSIRO (CSIROMk3.0), MRI (MRI-CGCM 2.3.2), and MIROC (MIROC-medres). These GCMs were selected because they could relatively accurately simulate current climate condition in Japan (not shown) and because they produced small, medium, and large warming rates, respectively. The global warming component derived from each GCM is individually added to the current weather conditions to yield three distinctive boundary conditions for future climate projections, thus resulting in three ensemble members, labeled with the prefix "PGW". A comparison of CTRL and PGW experiments will allow the projection of the change in urban climate due to global climate changes. We summarize all experimental cases in Table 5.

Table 5. Types of downscale experiments run in the present study. CTRL and NO_URBAN are baseline runs for the current climate, PGW is pseudo global warming method (Fig. A). Emission scenario means IPCC SRES A1b (IPCC, 2007).

\begin{tabular}{lclcc}
\hline Case & Emission Scenario & \multicolumn{1}{c}{ Boundary Conditions } & Period & Description \\
\hline CTRL & & NCEP Final Analysis (FNL) & $2000 \mathrm{~s}$ & \\
PGW_MRI & A1b & PWG data of MRI-CGCM2.3.2a & $2070 \mathrm{~s}$ & PGW experiment \\
PGW_MIROC & A1b & PGW data of MIROC3.2-medres & $2070 \mathrm{~s}$ & PGW experiment \\
PGW_CSIRO & A1b & PGW data of CSIRO-Mk3.0 & $2070 \mathrm{~s}$ & PGW experiment \\
NO_URBAN & & NCEP Final Analysis (FNL) & 2000s & No urban areas \\
\hline
\end{tabular}


For many results, we show the ensemble average of the three PGW cases.

For urban climate projections, we should also specify how the urban areas will change. But we assume constant urban parameters for all simulations because the three urban areas have already grown to a considerable extent and are unlikely to grow much over the next 70 years due to a) the stagnant Japanese economic situation (which has persisted over the last two decades) and b) the projected declines in demographic numbers.

\subsection{Results of urban climate projection in the $2070 \mathrm{~s}$}

The surface air temperatures over the domain increased by $2.0-2.5^{\circ} \mathrm{C}$ during the next 70 years (Fig. 7a,b). Indeed, the simulated future mean air surface temperature is comparable to that of the 2010 record-hot summer case shown in Figs. 4c,d, which suggests that the current abnormal weather condition could become the norm in the future climate. Moreover, the monthly mean daily maximum temperatures in the 2000s (Fig. 7c) and 2070s (Fig. 7d) show a clear daytime heat island effect in the inland areas of Tokyo, Osaka, and Nagoya. In the 2070s, the maximum temperatures in the inland areas often exceed $35^{\circ} \mathrm{C}$, which is considered extremely hot in Japan; indeed, the monthly averaged maximum temperatures are 32.6, 34.3, and $34.6^{\circ} \mathrm{C}$ in Tokyo, Nagoya, and Osaka stations, respectively. A nocturnal urban heat island also clearly occurs in Tokyo, Osaka, and Nagoya in both the 2000s and 2070s (Figs. 7e and 7f). The minimum temperature exceeds $26^{\circ} \mathrm{C}$ in these areas, which can make sleeping difficult.

Here, we explore the uncertainty associated with forcing GCMs. Figure 8 shows the range of warming from the three ensemble members for Tokyo, Osaka, and Nagoya between the 2070s and 2000s. We equate the range in predictions to the uncertainty. In all three cities, there is an uncertainty of nearly $2.2^{\circ} \mathrm{C}$. In particular, downscale simulation from MIROC resulted in the greatest warming, followed by MRI and then CSIRO, a pattern common to all three cities. In fact, this pattern exists throughout Japan (Fig. B), at other future dates (Fig. 1), as well as in the global average (IPCC 2007) due to the GCM models' differential sensitivity to anthropogenic forcing.

\subsection{Application to sleeping disorders and heat stress}

Now we apply these climate projection results to impact assessment study. According to the recent impact assessment research regarding human health (Ihara and Genchi 2009), sleep disorders begin to occur when temperatures remain above $26^{\circ} \mathrm{C}$ by midnight. For simplicity, we instead consider the nighttime minimum temperature and label those that exceed $26^{\circ} \mathrm{C}$ as heat-induced sleeping discomfort nights, or just HSD nights. In this section, we run a simple impact assessment on the frequency of HSD nights.

The simulated nighttime temperature is negatively biased in Tokyo, Osaka, and Nagoya (see $\S 2.2$ ) and thus the uncorrected model underestimates the frequency of HSD nights. For this reason, we bias-correct the midnight temperature by raising it by $1^{\circ} \mathrm{C}$ to match the observed cumulative probability distribution of midnight temperature. This bias-corrected temperature will be used in the following discussion on HSD nights.

All three ensemble members and all three cities show dramatic increases in the HSD nights (Fig. 9). In Tokyo, August of the 2070s has 30 HSD nights - one and a half times that in the 2000s and the same as that in 2010. Similarly, Osaka and Nagoya have 31 HSD nights. There was little model uncertainty in all three cities, being at most one day. Therefore, in Tokyo, Osaka, and Nagoya under the IPCC SRES A1b scenario, urban warming in the next 70 years will hinder sleep nearly every night. Such conditions are reminiscent of the record-hot summer of 2010 .

Heat stress, including heat stroke (heat disorder), is also a serious social problem in Japan, especially in large urban areas. In a normal summer (August 2007) and a hot one (August 2010), 23,071 and 53,843 people, respectively, were taken to hospitals by ambulance due to heat stroke. In this section, we examine the change in the heat index to conduct an impact assessment for heat stroke.

This study uses the wet-bulb globe temperature (WBGT) to estimate heat stress in future climates. As an empirical heat index, the WBGT, considers not only the dry-bulb temperature, but also the wet-bulb and globe temperatures. The WBGT was developed to help control heat casualties during military training, but is now widely used in Japan because it correlates better than air temperature to the number of heat stroke patients. Moreover, many organizations (e.g., the Ministry of the Environment, the Japanese Society of Biometeorology, and Japan amateur sports associations) recommend or use this index (specifically, standard ISO 7243) as a standard for heat stress risk, in- 


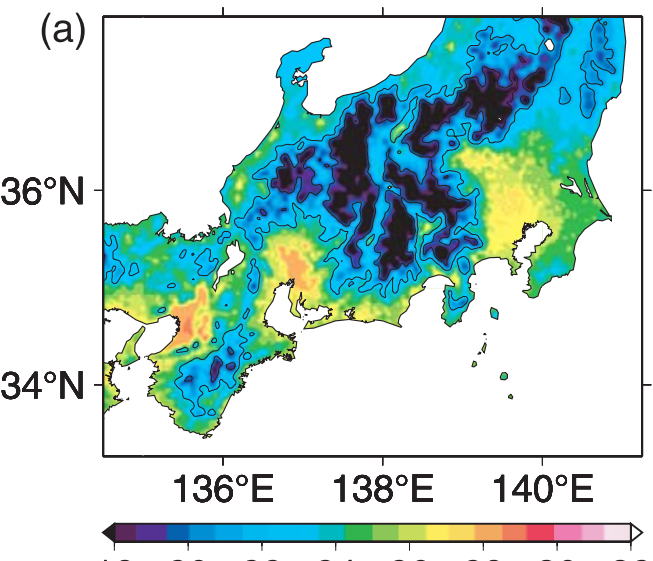

$\begin{array}{lllllllll}18 & 20 & 22 & 24 & 26 & 28 & 30 & 32 & \left({ }^{\circ} \mathrm{C}\right)\end{array}$

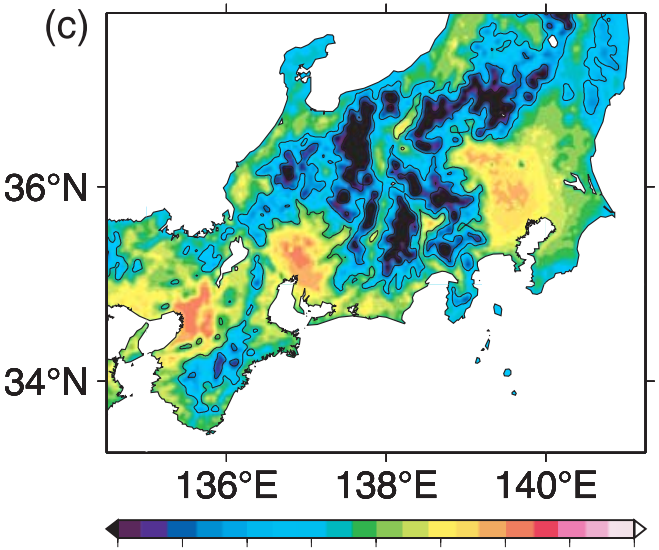

202224262830323436

$\left({ }^{\circ} \mathrm{C}\right)$

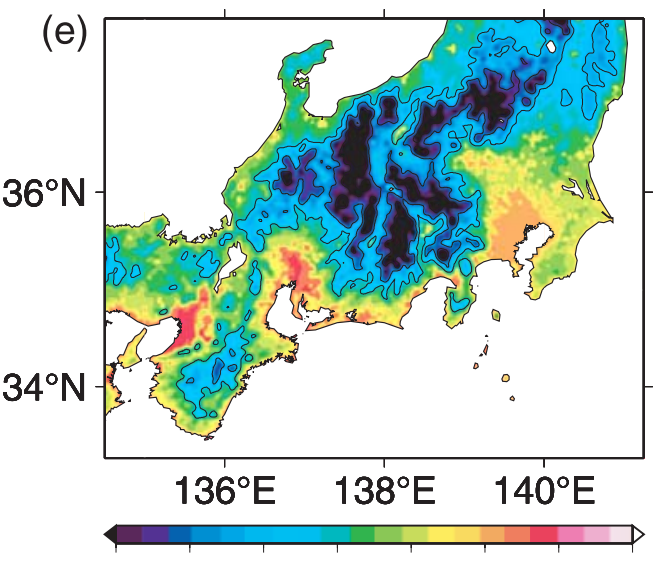

$\begin{array}{llllllll}14 & 16 & 18 & 20 & 22 & 24 & 26 & 28\end{array}$

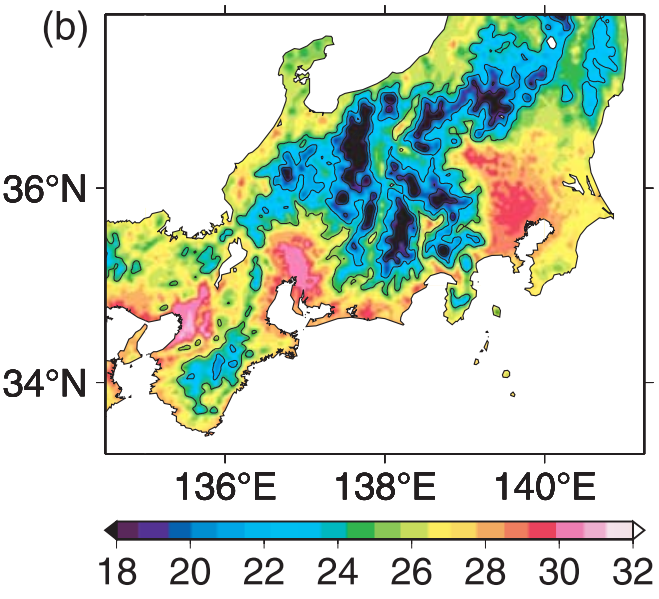

$\left({ }^{\circ} \mathrm{C}\right)$
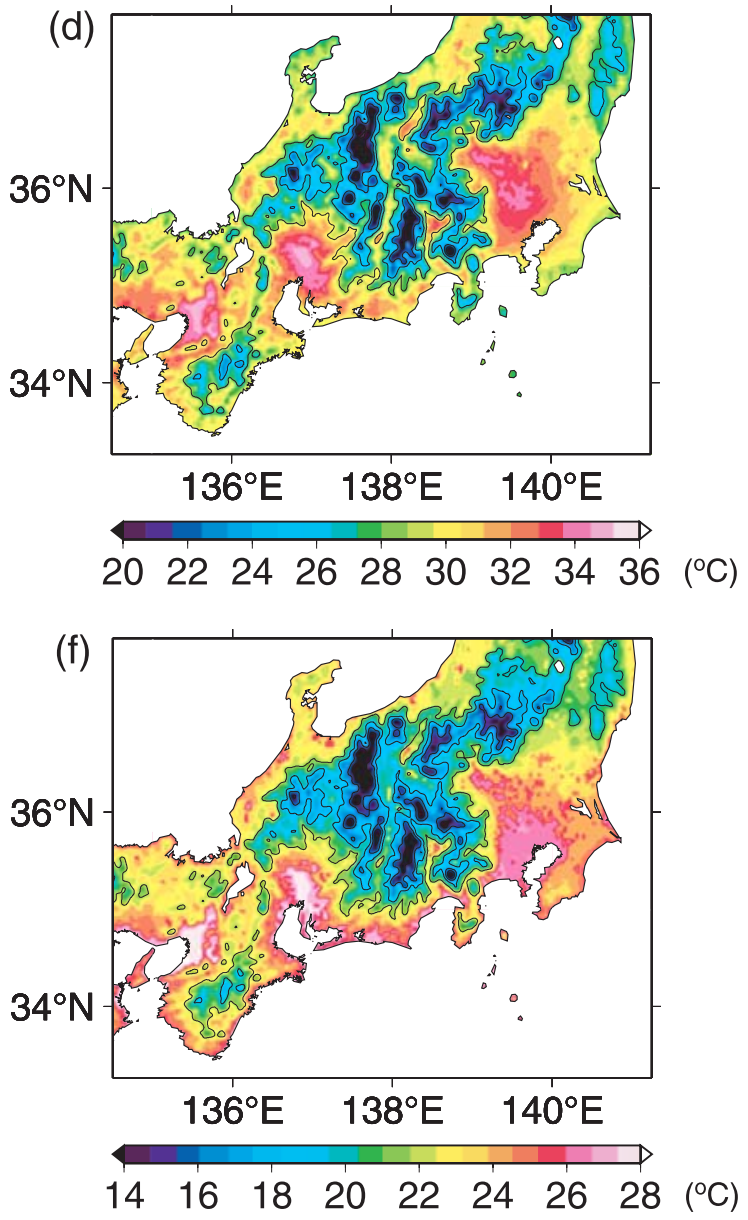

Fig. 7. August monthly mean surface air temperatures. (a) Climate in the 2000s, August (CTRL case). (b) Climate in the 2070s, August (PGW ensemble mean). (c) and (d) are the same as (a) and (b), but for the monthly mean daily maximum surface air temperature. (e) and (f) are the same as (a) and (b), but for the monthly mean daily minimum. 


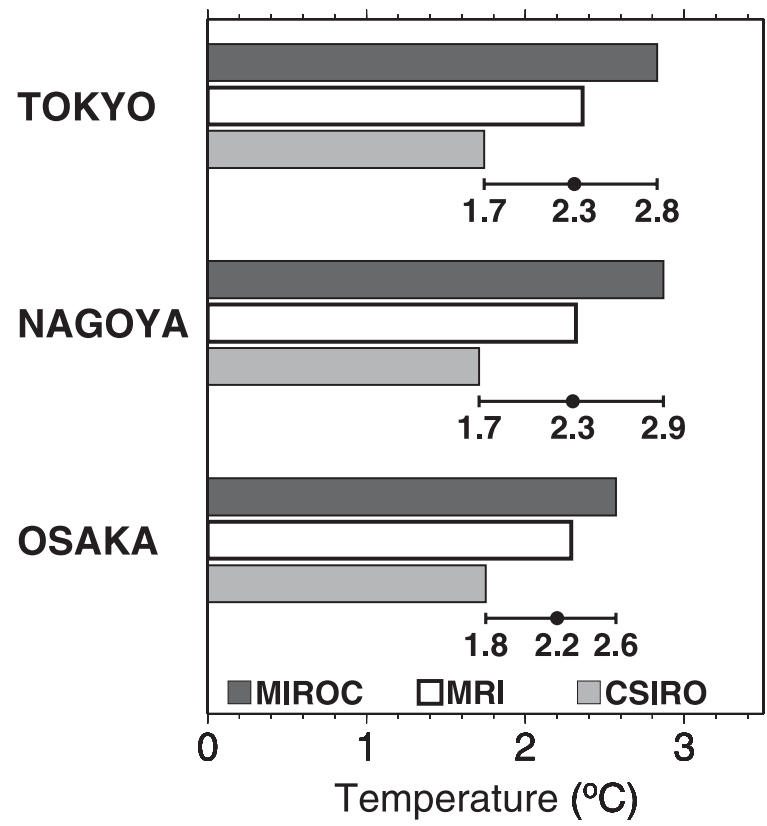

Fig. 8. Sensitivity of future change in surface air temperature in three urban areas from the three PGW ensemble members. Dots indicates the ensemble mean of the monthly average surface temperature. Error bars show minimum and maximum values. cluding heat stroke. The heat stress risk table has five categories: danger $\left(\mathrm{WBGT} \geq 31^{\circ} \mathrm{C}\right)$, alert $\left(28 \leq \mathrm{WBGT}<31^{\circ} \mathrm{C}\right)$, advisory $\left(25^{\circ} \mathrm{C} \leq \mathrm{WBGT}\right.$ $\left.<28^{\circ} \mathrm{C}\right)$, caution $\left(21^{\circ} \mathrm{C} \leq \mathrm{WBGT}<25^{\circ} \mathrm{C}\right)$, and mostly safe (WBGT $<21^{\circ} \mathrm{C}$ ), as summarized in Table 6.

The WBGT used in outdoor daylight conditions is given by the following formula:

$\mathrm{WBGT}=0.7 T_{w}+0.2 T_{g}+0.1 T_{d}$, where, $T_{w}\left({ }^{\circ} \mathrm{C}\right), T_{g}\left({ }^{\circ} \mathrm{C}\right)$, and $T_{d}\left({ }^{\circ} \mathrm{C}\right)$ are the wetbulb, globe, and dry-bulb temperatures, respectively. The globe temperature is often measured with a globe thermometer (but was not typically

Table 6. Heat stress risk levels based on the wet-bulb globe temperature (WBGT). Risk levels are from the Japan Sports Association (1996).

\begin{tabular}{lll}
\hline WBGT & \multicolumn{1}{c}{ Level } & \multicolumn{1}{c}{ Description } \\
\hline $31-$ & Danger & Consider stopping all exercise \\
$28-31$ & Alert & Stop strenuous exercise \\
$25-28$ & Advisory & Take rests frequently \\
$21-25$ & Caution & Frequent hydration needed \\
-21 & Mostly safe & Risk is relatively lower \\
\hline
\end{tabular}

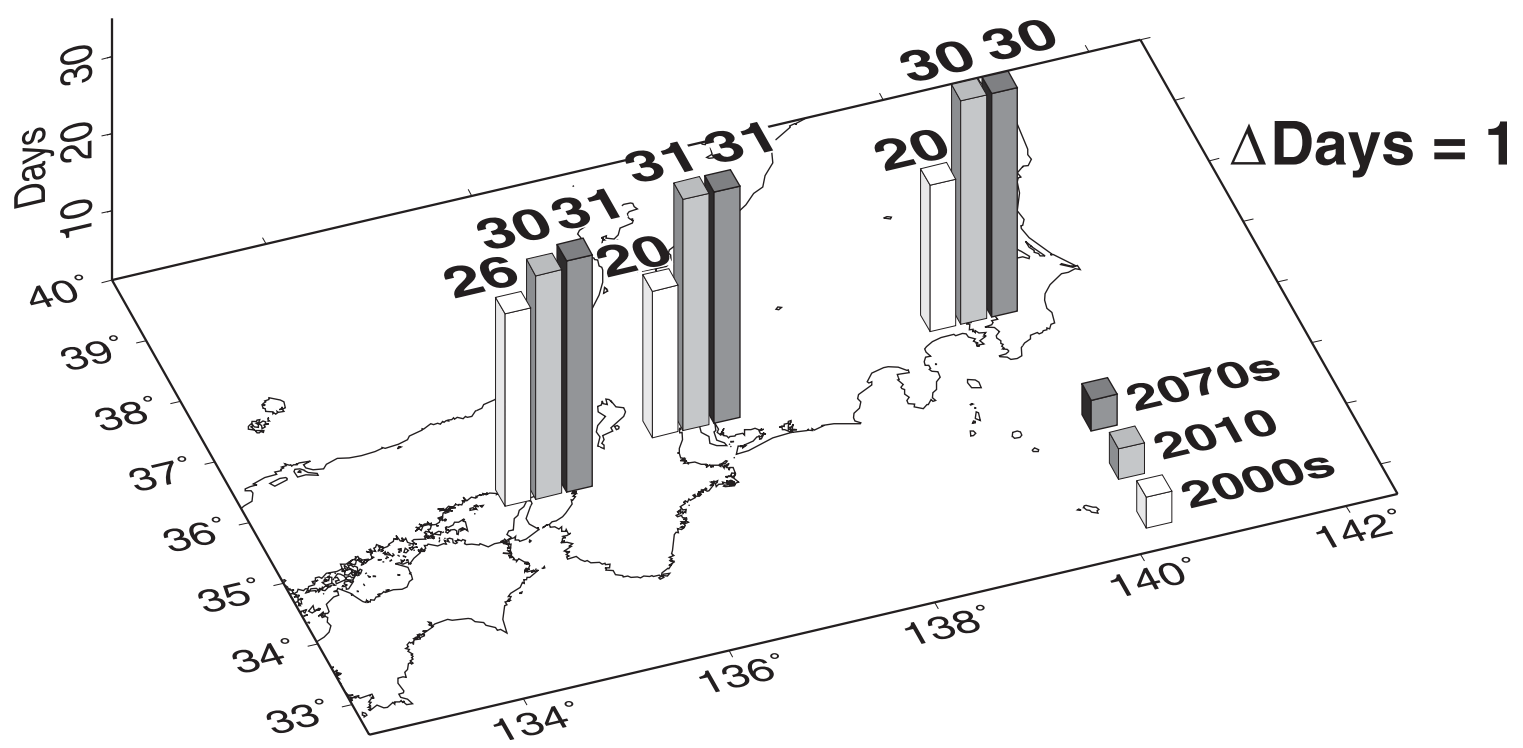

Fig. 9. Simulated number of days causing sleep disorders (i.e., minimum nighttime temperature exceeding $26^{\circ} \mathrm{C}$ ) in August for 2000s (white bars), 2010 (gray bars), and 2070s (dark bars) from the ensemble mean. $\triangle$ Days is the difference among the ensemble members. 
measured at meteorological stations in Japan until 2006). Since $T_{q}$ is not directly calculated in the WRF model, we use Tonouchi et al.'s (2006) empirical formula:

$$
T_{g}=T_{d}+0.017 S-0.208 U,
$$

where $S$ is the solar radiation $\left(\mathrm{W} \mathrm{m} \mathrm{m}^{-2}\right)$ and $U$ is the wind speed $\left(\mathrm{m} \mathrm{s}^{-1}\right)$. However, to match the observed cumulative frequency of daytime WBGT (Fig. C), we applied a bias-correction by raising the value by $0.5^{\circ} \mathrm{C}$.

Although the daytime cumulative frequency of the WBGT for the 2070s seems to shift only slightly from that of the 2000s, the number of heat-stress alerts increases dramatically for all three cities (Fig. 10). In Tokyo, the number of hours over the alert-level amounted to 112 in the 2000s' August (Table 7, based on Fig. 10a). This indicates that, in a normal summer under the current climate, the residents should stop strenuous exercise outdoors for $30 \%$ of the daytime hours. However, in the 2070s, the hours over the alert-level more than doubles, reaching 232, meaning that the residents will be warned to stop strenuous exercise outdoors for $62 \%$ of the daytime hours. In Nagoya and Osaka, the daytime thermal environment in the future is even less comfortable than in Tokyo, as is the case in the 2000s (Figs. 10b and 10c).

This increase of WBGT results from increases of each parameter within WBGT by approximately equal amounts (Table 8). Focusing on individual ensemble members, case MIROC projects an increase to $67 \%$ for the hours over the alert-level, whereas case CSIRO projects an increase of $54 \%$. Despite this range of values (uncertainty) from the GCMs, the results imply that incidences of heat stroke will dramatically rise in conjunction with global climate change under the IPCC SRES A1b scenario. As a result, the situation in which many heat stroke patients are taken to the hospital, as in a presently abnormally hot summer (August 2010), would occur even in a normal summer in the $2070 \mathrm{~s}$ (Table 7).

\section{Discussion}

Our analyses show that, under the IPCC SRES A1b scenario, urban residents would experience more sleep disorders and heat stroke unless mitigations efforts are made. The mitigation of urban heat islands should reduce the heat stress enhanced by climate change. But how much of the temperature rise in these cities is due to global climate change (a) $\quad \cdots$... Case CTRL —PGW-Ensemble

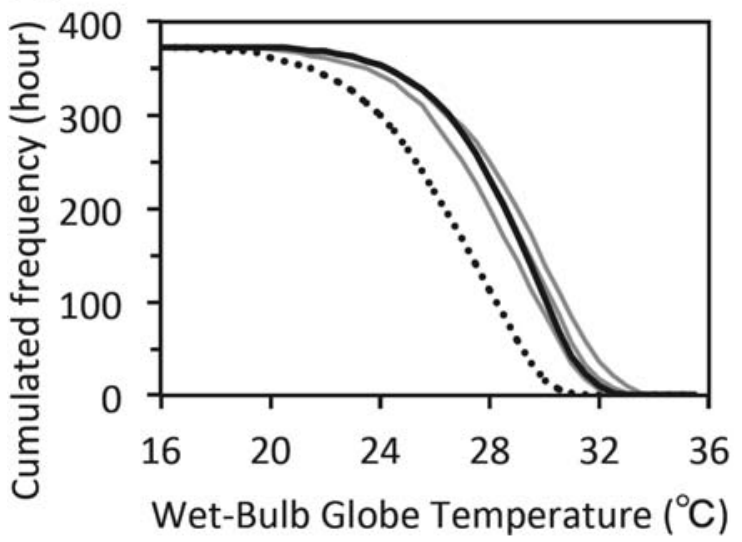

(b) $\quad \cdots$... Case CTRL —PGW-Ensemble
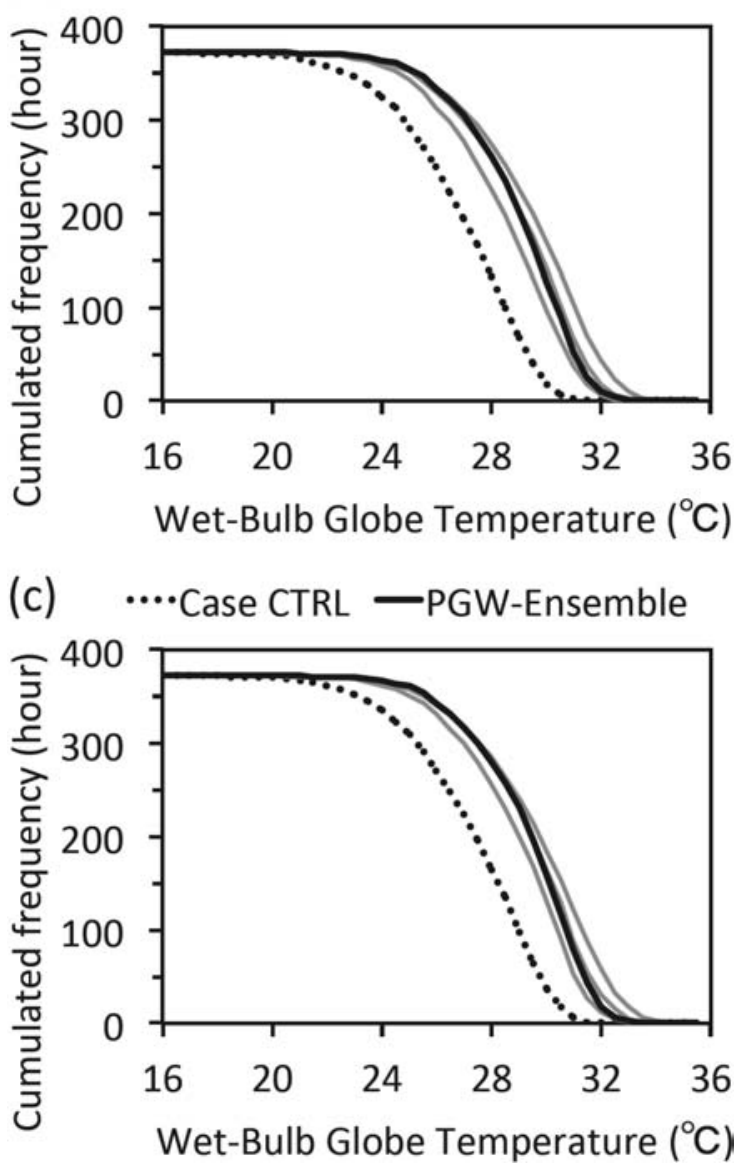

Fig. 10. Number of hours exceeding a given WBGT value in August for the CTRL case (2000s) and the PGW cases (2070s) in three urban areas. The three gray lines are from the three GCM cases, and the thick black curve is the ensemble average. (a) Tokyo, (b) Nagoya, and (c) Osaka. 
Table 7. Simulated total number of hours that exceed the WBGT levels of 25,28 , and $31^{\circ} \mathrm{C}$ in Tokyo. In parenthesis are their percentage of the total daytime hours in August (372 hours).

\begin{tabular}{|c|c|c|c|c|c|c|}
\hline & \multirow[t]{2}{*}{$2000 \mathrm{~s}$} & \multirow[t]{2}{*}{2010} & \multicolumn{4}{|c|}{$2070 \mathrm{~s}$} \\
\hline & & & Ensemble & MIROC & MRI & CSIRO \\
\hline $31^{\circ} \mathrm{C}$ & $2(1 \%)$ & $21(6 \%)$ & $43(12 \%)$ & $84(23 \%)$ & $56(15 \%)$ & $34(9 \%)$ \\
\hline $28^{\circ} \mathrm{C}$ & $112(30 \%)$ & $230(62 \%)$ & $232(62 \%)$ & $249(67 \%)$ & $232(62 \%)$ & $200(54 \%)$ \\
\hline $25^{\circ} \mathrm{C}$ & $264(71 \%)$ & $350(94 \%)$ & $337(91 \%)$ & $338(91 \%)$ & $336(90 \%)$ & $322(87 \%)$ \\
\hline
\end{tabular}

Table 8. Simulated August mean WBGT and its components (globe, wet-bulb, and dry-bulb temperatures) for three urban areas. ENSEMBLE is the ensemble average of MRI, MIROC, and CSIRO, whereas Diff. is the difference between ENSEMBLE and CTRL.

\begin{tabular}{|c|c|c|c|c|}
\hline Tokyo & $0.2 \mathrm{Tg}$ & $0.7 T w$ & $0.1 T d$ & WBGT \\
\hline CTRL & 7.2 & 15.7 & 2.8 & 25.7 \\
\hline MRI & 7.8 & 17.2 & 3.0 & 28.0 \\
\hline MIROC & 7.8 & 17.5 & 3.1 & 28.4 \\
\hline CSIRO & 7.6 & 16.8 & 3.0 & 27.4 \\
\hline ENSEMBLE & 7.6 & 16.8 & 3.0 & 27.4 \\
\hline Diff. & 0.4 & 1.1 & 0.2 & 1.7 \\
\hline Nagoya & $0.2 \mathrm{Tg}$ & $0.7 T w$ & $0.1 T d$ & WBGT \\
\hline CTRL & 7.6 & 15.8 & 2.9 & 26.3 \\
\hline MRI & 8.1 & 17.2 & 3.2 & 28.5 \\
\hline MIROC & 8.1 & 17.5 & 3.2 & 28.8 \\
\hline CSIRO & 7.9 & 16.8 & 3.1 & 27.8 \\
\hline ENSEMBLE & 7.9 & 16.8 & 3.1 & 27.8 \\
\hline Diff. & 0.4 & 1.0 & 0.2 & 1.6 \\
\hline Osaka & $0.2 \mathrm{Tg}$ & $0.7 T w$ & $0.1 T d$ & WBGT \\
\hline CTRL & 7.8 & 16.0 & 3.0 & 26.8 \\
\hline MRI & 8.3 & 17.3 & 3.2 & 28.8 \\
\hline MIROC & 8.3 & 17.6 & 3.2 & 29.1 \\
\hline CSIRO & 8.2 & 17.0 & 3.2 & 28.4 \\
\hline ENSEMBLE & 8.1 & 17.0 & 3.1 & 28.2 \\
\hline Diff. & 0.3 & 1.0 & 0.2 & 1.5 \\
\hline
\end{tabular}

and how much is due to the urban heat island effect?

Over the next 70 years, the urban warming due to the urban heat island intensity (UHII) is comparable to that from global climate change. To evaluate the present UHII, we compare the urban temperature in case CTRL with that in which the urban areas are replaced by grassland, hereafter case NO_URBAN. The difference between the two cases equals the UHII. At Nerima station, the resulting UHII is greater at around sunset and sunrise than in the daytime (Fig. 11), which agrees with previous urban climate studies, and the monthly mean UHII is $1.5^{\circ} \mathrm{C}$. In support of this estimate, the monthly mean temperature difference between Tokyo station and the nearby rural station at Choshi for the 2000 s equals $2.1^{\circ} \mathrm{C}$ (Table 1). We also find (but do not show) that the daily mean and diurnal variation of UHII in the future is almost identical to those of the present. Thus, since the UHII of $1.5^{\circ} \mathrm{C}$ nearly equals the overall warming of $2.3^{\circ} \mathrm{C}$ for Tokyo (Fig. 8), mitigation of UHI 


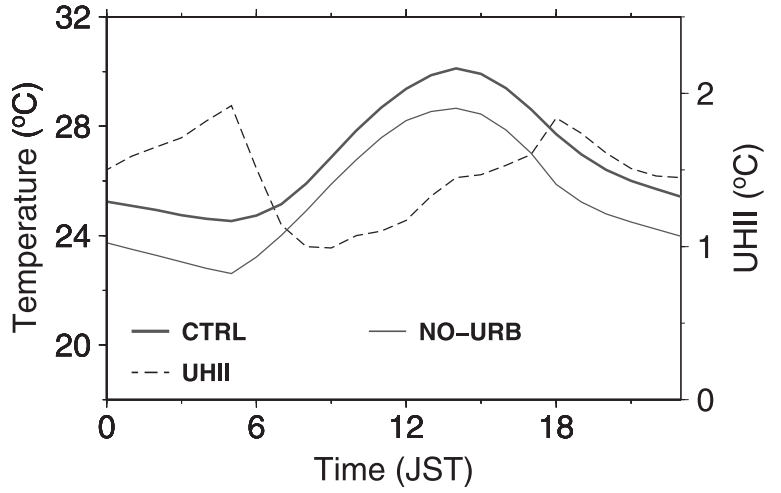

Fig. 11. Diurnal variation of the urban heat island intensity (UHII) for the 2000s in Tokyo (August average). CTRL curve shows the simulated urban temperature, whereas the NO_URB curve shows the same region as grassland. The UHII is the difference of the curves.

should reduce future urban residents' heat stress. An example of mitigation approaches would be constructing compact cities as suggested by, for instance, Stone et al. (2010).

Urban climate projection is affected by uncertainties due to the urban scenario itself. Dynamical downscaling with various urban scenarios will help us plan to mitigate urban heat islands and thus to adapt to the consequences of global climate change.

McCarthy et al. (2010) and Oleson et al. (2010) report that future change of UHII varies by region in future climate due to an increase in $\mathrm{CO}_{2}$. However, the dynamical downscaling in the present study showed little change in the strength of the UHII, at least in central Japan. There are several potential reasons for the little change in future UHII projected in this study. First, McCarthy et al. (2010) and Olsen et al. (2010) doubled the future $\mathrm{CO} 2$ concentrations, while the current climate $\mathrm{CO} 2$ concentration is kept unchanged throughout the simulation in this study. Second, McCarthy et al. (2010) and Olsen et al. (2010) assessed the annual mean changes, whereas the current study focused on summer months. Last, the PGW method used in this study conserves the majority of current synoptic-scale variations in future climate, including frequency of clear days and daily wind speed variations. The monthly mean UHII is sensitive to such synoptic scale conditions. Hence the PGW method may be one of the reasons for the little change in UHII projected in this study. To overcome this limitation, we plan to use a direct dynamical downscaling method in a future study.

Although the PGW approach precludes a detailed analysis of interannual variations in future climate, we can nevertheless consider what may happen if the large-scale patterns that have occurred during abnormally hot or cold summer years also appear in the 2070s. The results show that the urban temperatures during a cold summer year may become comparable to the current normal temperatures (Fig. 12a and Figs. 4a,b), but may rise above $32^{\circ} \mathrm{C}$ in a hot summer year (Fig. 12b).
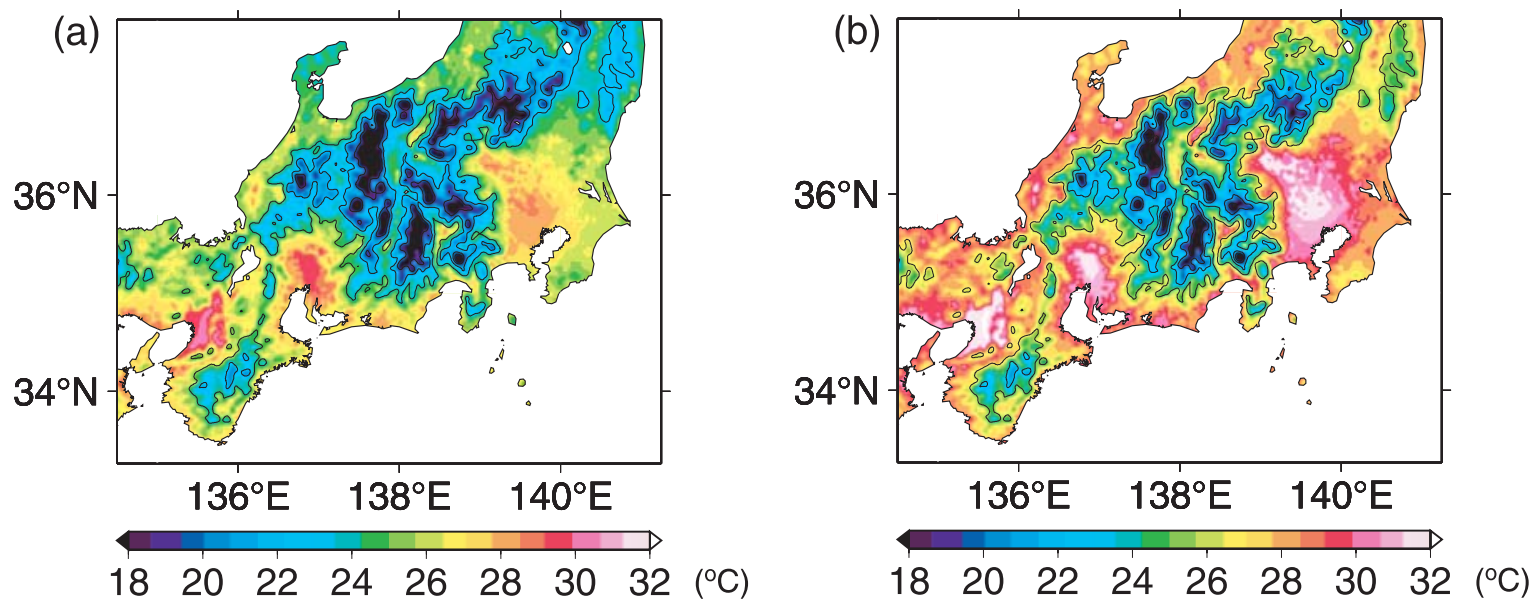

Fig. 12. Projected monthly mean surface air temperature for relatively cold and hot summer cases. Projections are for the 2070s August. 
However, further discussion requires a reduction of uncertainties of GCMs at interannual timescales.

\section{Summary}

In this study, we evaluated the performance of the WRF model (3-km horizontal grid spacing) coupled with a single-layer UCM, and then applied the model to urban climate projections for August in the 2070s. We applied the model to central Japan, focusing on the three major urban areas, and assumed the IPCC SRES A1b scenario. After that, we estimated GCM uncertainties and made simple impact assessments to heat stress. Finally, the UHII was estimated and compared to urban warming due to the global climate change in the next 70 years. The results are summarized below.

(1) The model reproduced essential features of the observed monthly mean surface air temperature distribution: the three major urban areas were warmer than their surroundings, and the temperatures in Osaka and Nagoya were higher than those in Tokyo. The average bias over the entire domain was $-1.2^{\circ} \mathrm{C}$, mainly due to differences over the mountainous areas. But for Tokyo, Nerima, Nagoya, Osaka, and Sakai stations, the biases were $-0.6,-0.3,-0.1,-0.4$, and $+0.1^{\circ} \mathrm{C}$. Moreover, the diurnal variation of the urban temperature was well reproduced, indicating that the WRF model is a useful tool to simulate and project urban climate.

(2) The urban climate projection found the urban warming in the next 70 years to be $2.5,2.3$, and $2.3^{\circ} \mathrm{C}$ near Tokyo, Nagoya, and Osaka stations, respectively. At Tokyo, the monthly mean temperature was $29^{\circ} \mathrm{C}$, which roughly equals that in the record-hot summer of 2010. The monthly maximum temperature in inland areas exceeded $35^{\circ} \mathrm{C}$, which is extremely hot for Japan, and was 32.9, 33.4 , and $34.7^{\circ} \mathrm{C}$ in Tokyo, Nagoya, and Osaka, respectively.

(3) The three ensemble members gave predictions of average temperature in the 2070 s that ranged by about $1.2^{\circ} \mathrm{C}$.

(4) The total number of days with conditions that trigger sleep disorders (HSD nights) reached 30 for the 2070s' August in Tokyo-one and a half times as many days as in the 2000 s and roughly equal to that from the record-hot summer of 2010. All three ensemble members agreed within one day.

(5) Concerning heat-stroke conditions, the results suggested that heat stroke will rise in frequency in the future. For Tokyo, the hours exceeding the WBGT alert-level rose from 112 in the 2000s' Au- gust to 232 in the 2070s. The corresponding warning to the residents to avoid strenuous outdoor exercise rose from $30 \%$ of the daytime hours in the 2000 s to $62 \%$ in the 2070 s. (The ensemble members varied in this prediction by $13 \%$.) As a result, the number of heat stroke patients taken to the hospital in the record-hot summer of August 2010 would likely recur in the 2070s. In Nagoya and Osaka, the daytime thermal environment in the future was found to be even less comfortable than that in Tokyo.

(6) The monthly mean strength of the UHII in the present-climate was $1.5^{\circ} \mathrm{C}$, which nearly equals the warming from the PGW experiment. Considering that this UHII value nearly equals the urban warming from global climate change in the next 70 years, mitigation of UHII will reduce residents' heat stress in the future, although the impacts will be limited to the urban areas and their immediate surroundings.

\section{Acknowledgements}

We thank Ms. Manami Ishikawa of the University of Tsukuba for making several figures and Mr. Tomoyuki Takata of Kanagawa Prefecture for running the preliminary experiments while in graduate school of the University of Tsukuba. Also, Dr. Asuka Suzuki-Parker of the University of Tsukuba helped to improve the manuscript. This study was supported by the Global Environment Research Fund (S-5) of the Ministry of the Environment, Japan. Numerical simulations for the present work were done under the "Interdisciplinary Computational Science Program" in the Center for Computational Sciences, University of Tsukuba.

\section{Appendix A}

CTRL and PGW procedure used in the present study

Hindcast experiment (simulation of past/present climate)

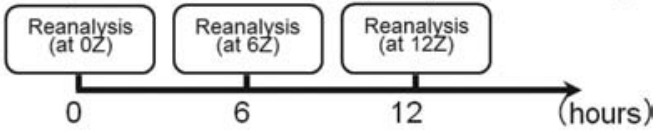

PGW experiment

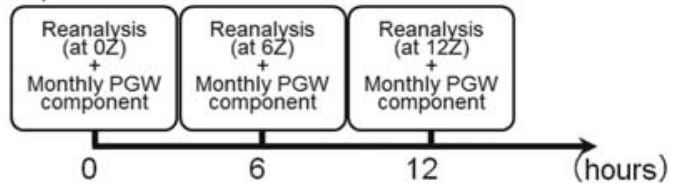




\section{Appendix B}

August monthly mean surface air temperatures. Climate in the 2070s, August (PGW three ensemble members).

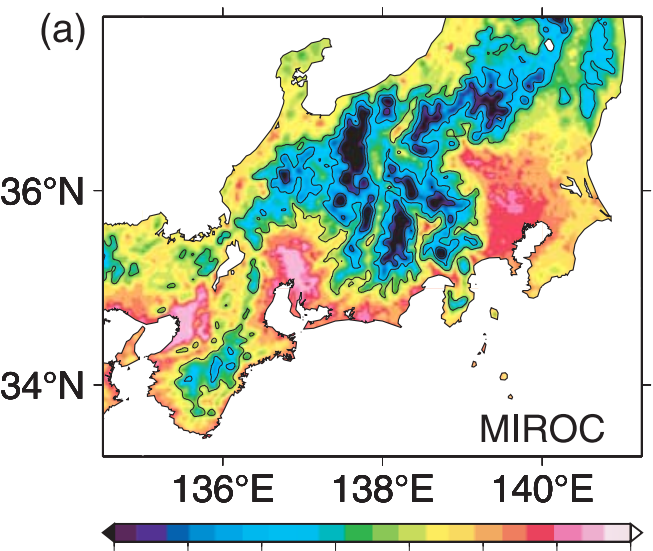

$\begin{array}{llllllll}18 & 20 & 22 & 24 & 26 & 28 & 30 & 32\end{array}$
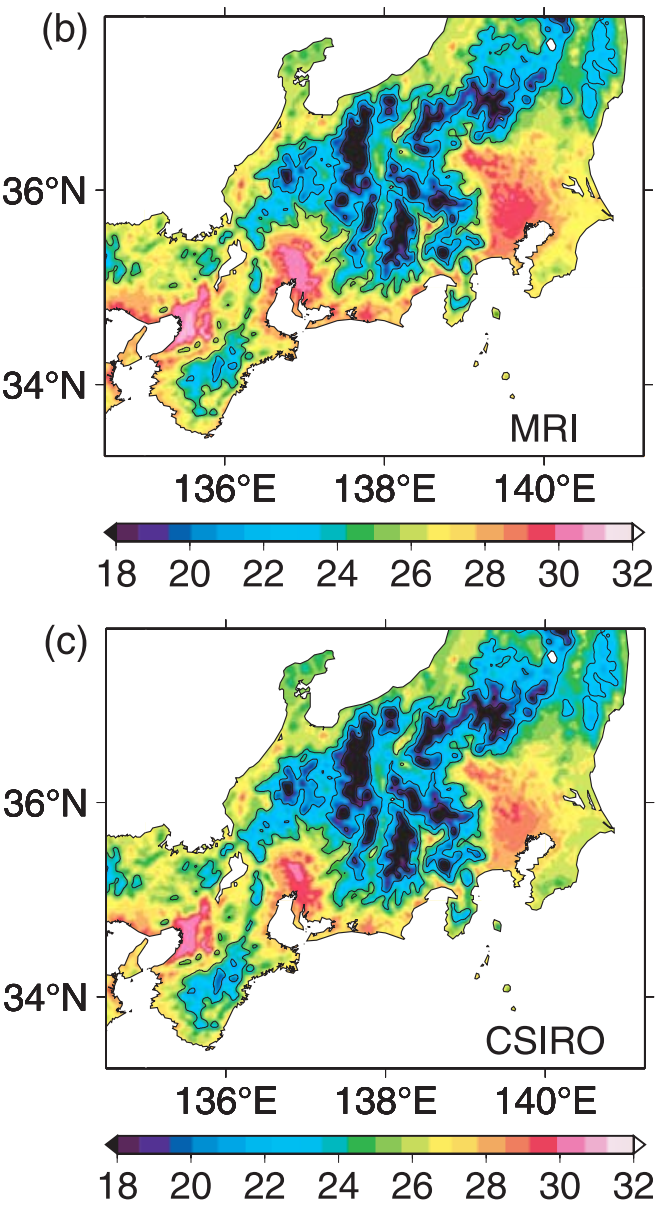

Appendix C

Number of hours exceeding a given WBGT value in August for the CTRL case (2000s). Before and after bias-correction

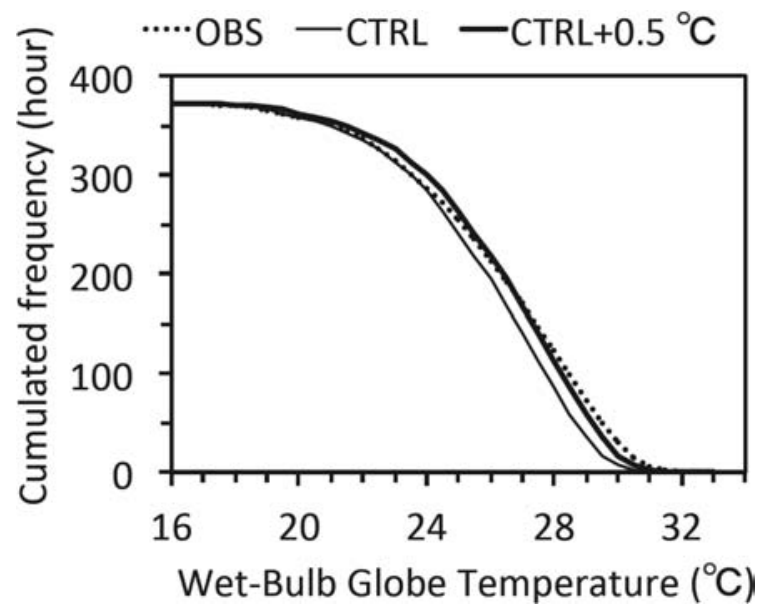

\section{References}

Catro, C. L., R. A. Pielke Sr., and G. Leconcini, 2005: Dynamical downscaling: Assessment of value retained and added using the Regional Atmospheric Modeling System (RAMS). J. Geophys. Res., 110, D05108, doi:10.1029/2004JD004721.

Chen, F., and J. Dudhia, 2001: Coupling an advanced land-surface/hydrology model with the Penn State/ NCAR MM5 modeling system. Part I: Model description and implementation. Mon. Wea. Rev., 129, 569-585.

Chen, F., H. Kusaka, R. Bornstein, J. Ching, C. S. B. Grimmond, S. Grossman-Clarke, T. Loridan, K. W. Manning, A. Martilli, S. Miao, D. Sailor, F. P. Salamanca, H. Taha, M. Tewari, X. Wang, A. A. Wyszogrodzki, and C. Zhang, 2010: The integrated WRF/urban modeling system: Development, evaluation, and applications to urban environmental problems. Int. J. Clim., 31, 273 288.

Dickinson, R. E., R. M. Errico, F. Giorgi, and G. T. Bates, 1989: A regional climate model for the western U.S. Climatic Change, 15, 383-422.

Dudhia, J., 1989: Numerical study of convection observed during the winter monsoon experiment using a mesoscale two-dimensional model. $J$. Atmos. Sci., 46, 3077-3107.

Dudhia, J., 1993: A nonhydrostatic version of the Penn State/NCAR mesoscale model: Validation tests and simulations of an Atlantic cyclone and cold front. Mon. Wea. Rev., 121, 1493-1513.

Fire and Disaster Management Agency of Japan, 2011: 
http://www.fdma.go.jp/neuter/topics/heatstroke/ pdf/221029/syuukeikekka_01.pdf (in Japanese).

Fischer, E. M., and C. Schär, 2010: Consistent geographical patterns of changes in high-impact European heatwaves. Nature Geoscience, doi:10.1038/ NGEO866.

Fujibe, F., 2009: Detection of urban warming in recent temperature trends in Japan. Int. J. Clim., 29, 1811-1822.

Fruh, B., P. Becker, T. Deutschlander, J.-D. Hessel, M. Kossmann, I. Mieskes, J. Namyslo, M. Roos, U. Sievers, T. Steigerwald, H. Turau, and U. Wienert, 2011: Estimation of climate-change impacts on the urban heat load using an urban climate model and regional climate projections. J. Appl. Meteor. Clim., 50, 167-184.

Giorgi, F., and T. Bates, 1989: The climatological skill of a regional model over complex terrain. Mon. Wea. Rev., 117, 2325-2347.

Goto, K., K. Yabe, and N. Araki, 2004: Estimation of maximum demand sensitivity to the temperature for long-term power demand forecast. Proc. Technical Meeting of Power and Energy Division 2004, The Institute of Electrical Engineers of Japan, 13 21 (in Japanese).

Grell, G. A., J. Dudhia, and D. R. Stauffer, 1994: A description of the fifth-generation Penn State/NCAR Mesoscale Model (MM5). NCAR/TN-398+STR, National Center for Atmospheric Research, http:// www.ncar.ucar.edu.

Hara, M., T. Yoshikane, H. Kawase, and F. Kimura, 2008: Estimation of the impact of global warming on snow depth in Japan by the Pseudo-GlobalWarming method. Hydrol. Res. Lett., 2, 61-64, doi:10.3178/hrl.2.61.

Hara, M., H. Kusaka, F. Kimura, and Y. Wakazuki, 2010: Effect of global climate change on urban heat island intensity of Tokyo metropolitan areawinter season case- - Nagare, 29, 353-361 (in Japanese with English abstract).

Honda, Y., M. Ono, A. Sasaki, and I. Uchiyama, 1998: Shift of the short-term temperature-mortality relationship by a climate factor-some evidence necessary to take account of in estimating the health effect of global warming. J. Risk Res., 1, 209-220.

Hong, S.-Y., and H.-L. Pan, 1996: Nonlocal boundary layer vertical diffusion in a medium-range forecast model. Mon. Wea. Rev., 124, 2322-2339.

Hong, S.-Y., J. Dudhia, and S.-H. Chen, 2004: A revised approach to ice microphysical processes for the bulk parameterization of clouds and precipitation. Mon. Wea. Rev., 132, 103-120.

Hong, S.-Y., Y. Noh, and J. Dudhia, 2006: A new vertical diffusion package with an explicit treatment of entrainment processes. Mon. Wea. Rev., 134, 2318-2341.

Ihara, T., Y. Genchi, T. Sato, K. Yamaguchi, and Y.
Endo, 2008: City-block-scale sensitivity of electricity consumption to air temperature and air humidity in business districts of Tokyo, Japan. Energy, 33, 1634-1645.

Ihara, T., and Y. Genchi, 2009: Environmental impact assessment of urban air temperature increase based on endpoint-type life cycle impact (Part 2)Quantification of environmental impact in Tokyo. Proceedings of the 7th International Conference on Urban Climate (ICUC-7), Yokohama Japan, in CD-ROM.

Ihara, T., H. Kusaka, M. Hara, R. Matsuhashi, and Y. Yoshida, 2011: Estimation of mild health disorder caused by urban air temperature increase with midpoint-type impact assessment methodology. $J$. Environ. Eng., AIJ, 76, 459-467 (in Japanese with an English abstract).

Iizuka, S., K. Kinbara, H. Kusaka, M. Hara, and Y. Akimoto, 2010: Numerical simulation of current status of summer and an attempt to project a future thermal environment combined with pseudo global warming data. J. Environ. Eng. (Transcations of AIJ), 647, 87-93 (in Japanese with an English abstract).

IPCC, 2007: Climate change 2007: The physical science basis. Contribution of working group I to the fourth assessment report of the intergovernmental panel on climate change, S. Solomon et al., Eds., Cambridge University Press, 996 pp.

Japan Sports Association, 2006: Guidebook for prevention of heat stroke on the exercise $2^{\text {nd }}$ edition. $48 \mathrm{pp}$ (in Japanese).

Japan Meteorological Agency, 2009: Climate change monitoring report 2008, $89 \mathrm{pp}$. [Available online at http://ds.data.jma.go.jp/tcc/tcc/products/gwp/ gwp.html] (in Japanese).

Jiang, X. Y., C. Wiedinmyer, F. Chen, Z. L. Yang, and J. C. F. Lo, 2008: Predicted impacts of climate and land use change on surface ozone in the Houston, Texas, area. J. Geophys. Res., 113, doi:10.1029/2008JD009820.

Kain, J. S., and J. M. Fritsch, 1990: A one-dimensional entraining/detraining plume model and its application in convective parameterization. J. Atmos. Sci., 47, 2784-2802.

Kain, J. S., 2004: The Kain-Fritsch convective parameterization: An update. J. Appl. Meteor., 43, 170-181.

Kanada, S., M. Nakano, and T. Kato, 2011: Projection of future changes in precipitation and vertical structures of the frontal zone during the Baiu season in the vicinity of Japan using a 5-km-mesh regional climate model. J. Meteor. Soc. Japan, submitted.

Kida, H., T. Koide, H. Sasaki, and M. Chiba, 1991: A new approach to coupling a limited area model with a GCM for regional climate simulations. J. Meteor. Soc. Japan, 69, 723-728. 
Kimura, F., and A. Kitoh, 2007: Downscaling by pseudo global warming method. The Final Report of the ICCAP, Research Institute for Humanity and $\mathrm{Na}$ ture, Kyoto, Japan.

Kitoh, A., T. Ose, K. Kurihara, S. Kusunoki, M. Sugi, and KAKUSHIN Team-3 Modeling Group, 2009: Projection of changes in future weather extremes using super-high-resolution global and regional atmospheric models in the KAKUSHIN Program: Results of preliminary experiments. Hydrol. Res. Lett., 3, 49-53.

Kusaka, H., H. Kondo, Y. Kikegawa, and F. Kimura, 2001: A simple single-layer urban canopy model for atmospheric models: Comparison with multilayer and slab models. Bound.-Layer Meteor., 101, 329-358.

Kusaka, H., and F. Kimura, 2004a: Coupling a singlelayer urban canopy model with a simple atmospheric model: Impact on urban heat island simulation for an idealized case. J. Meteor. Soc. Japan, 82, 67-80.

Kusaka, H., and F. Kimura, 2004b: Thermal effects of urban canyon structure on the nocturnal heat island: Numerical experiment using mesoscale model coupled with urban canopy model. J. Appl. Meteor., 43, 1899-1910.

Kusaka, H., T. Takata, and Y. Takane, 2010: Reproducibility of regional climate in central Japan using the 4-km resolution WRF model. SOLA, 6, 113116.

Kusaka, H., F. Chen, M. Tewari, J. Dudhia, D. Gill, M. G. Duda, W. Wang, and Y. Miya, 2012: Numerical simulation of urban heat island effect by the WRF model with 4-km grid increment: An inter-comparison study between the urban canopy model and slab model. J. Meteor. Soc. Japan, 90B, 33-46.

Liu, C., K. Ikeda, G. Thompson, R. Rasmussen, and J. Dudhia, 2011: High-resolution simulations of wintertime precipitation in the Colorado Headwaters region: sensitivity to physics parameterizations. Mon. Wea. Rev. doi:10.1175/MWR-D-11-00009.1, in press.

McCarthy, M. P., M. J. Best, and R. A. Betts, 2010: Climate change in cities due to global warming and urban effects. Geophy. Res. Lett., 37, L09705, doi:10.1029/2010GL042845.

Mearns, L. O., F. Giorgi, P. Whetton, D. Pabon, M. Hulme, and M. Lal, 2003: Guidelines for use of climate scenarios developed from regional climate model experiments. IPCC Task Group on Scenarios for Climate Impact Assessment (TGCIA). http://www.ipcc-data.org/guidelines/dgm_no1_v1 _10-2003.pdf.

Miao, S., F. Chen, M. A. Lemone, M. Tewari, Q. Li, and Y. Wang, 2009: An observational and modeling study of characteristics of urban heat island and boundary layer structures in Beijing. J. Appl. Meteor. Clim., 48, 484-501.

Miller, N. L., K. Hayhoe, J. Jin, and M. Auffhammer, 2008: Climate, extreme heat, and electricity demand in California. J. Appl. Meteor. Clim., 47, 1834-1844.

Ministry of Health, Labor and Welfare, 2011: http:// www.mhlw.go.jp/stf/houdou/2r9852000001g7agatt/2r9852000001g7fo.pdf.

Mlawer, E. J., S. J. Taubman, P. D. Brown, M. J. Iacono, and S. A. Clough, 1997: Radiative transfer for inhomogeneous atmospheres: RRTM, a validated correlated- $k$ model for the longwave. J. Geophys. Res., 102 (D14), 16663-16682.

Oleson, K. W., G. B. Bonan, J. Feddema, and T. Jackson, 2010: An examination of urban heat island characteristics in a global climate model. Int. J. Clim., doi:10.1002/joc.2201.

Rasmussen, R., K. Ikeda, C. Liu, D. Gochis, D. Yates, F. Chen, M. Tewari, M. Barlage, J. Dudhia, W. $\mathrm{Yu}$, K. Miller, K. Arsenault, V. Grubišić, G. Thompson, E. Gutmann, 2011: High-resolution coupled climate runoff simulations of seasonal snowfall over Colorado: A process study of current and warmer climate. J. Climate, 24, 3015-3048.

Sasaki, H., K. Kurihara, I. Takayabu, and T. Uchiyama, 2008: Preliminary experiments of reproducing the present climate using the non-hydrostatic regional climate model. SOLA, 4, 25-28.

Shepherd, J. M., M. Carter, M. Manyin, D. Messen, and S. Burian, 2010: The impact of urbanization on current and future coastal precipitation: A case study for Houston. Environment and planning B: Planning and Design, 37, 284-304.

Skamarock, W. C., J. B. Klemp, J. Dudhia, D. O. Gill, D. M. Barker, M. G. Duda, X.-Y. Huang, W. Wang, and J. G. Powers, 2008: A description of the advanced research WRF version 3. NCAR/ $T N-475+S T R, 113 \mathrm{pp}$.

Stone, B., Jr., J. Hess, and H. Frumkin, 2010: Urban Form and Extreme Heat Events: Are Sprawling Cities More Vulnerable to Climate Change Than Compact Cities? Environ Health Perspect. 118, $1425-1428$

Takahashi, K., Y. Honda, and E. Emori, 2007: Assessing mortality risk from heat stress due to global warming. J. Risk Res., 10, 339-354.

Tonouchi, M., K. Murayama, and M. Ono, 2006: WBGT forecast for prevention of heat stroke in Japan. Sixth Symposium on the Urban Environment, American Meteorological Society, Session PJ1.1.

Yamagata, Y., H. Bagan, H. Seya, and K. Nakamichi, 2010: Geographically explicit urban land use change scenarios for mega cities: A case study in Tokyo. Proceedings of 2010 AGU Fall Meeting, San Francisco, CA, USA, 13-17. 